\title{
Automated allocation of Distributed Generators using PSO based optimization approach
}

\author{
Praveen Kumar Raghuvanshi, ${ }^{1}$, \\ ${ }^{1}$ Assistant Professor, ABES Engineering College, Ghaziabad, India, onlypraveen1@ gmail.com
}

\begin{abstract}
Distributed Generation (DG) has gained more attention as it uses renewable and non-renewable small energy sources. Distributed generators are neither centrally placed nor dispatchable. It is scattered within the distribution system at or near load Centre. Distributed generation playing important role in the field of the electricity generation whereas Different issues related to power quality when DG is integrated with the existing power system has been discussed in the report. Distributed Generation is the best way to bridge the gap between supply and demand by reducing losses and carbon foot prints. Rural and remote areas can be electrified by these technologies.
\end{abstract}

Key words: Distributed generator (DG), Optimum location, PSO, Plug-in Electric Vehicle (PEV)

\section{INTRODUCTION}

Distributed generator (DG) placement in distribution system is one of the important tasks for better operation of distribution system. Distribution system has high $\mathrm{r} / \mathrm{x}$ ratio and high operating current resulting into higher power loss and higher voltage drop. The main objective of this work is to minimize the active power loss and to improve voltage profile of overall system by optimal sizing and sitting of DG. This work will present application of different optimization technique namely Particle swarm optimization (PSO) for optimal placement of distributed generators. The methods will be tested with IEEE standard test cases of radial distribution network and the results obtained by algorithms will be compared with non-optimal solutions.

Traditionally, electric power utilities have responded to peak load demand by constructing extra infrastructures. In the existing power grids, $20 \%$ of the entire generation capacity corresponds to meeting the peak load demand only. In other words, it is in use only for $5 \%$ of the overall operating time [2]. The next-generation electricity grid, which is known as "smart grid", is expected to deal with this peak load demand by driving toward maximum utilization of existing electricity infrastructures with tight operating margins. In addition, distributed generators (DGs) based on renewable energies such as fuel cell, photovoltaic, wind power, etc., have been given great attention worldwide in the last decade [1]-[3]. The rapid increase of load demand in developed countries is expected to be a serious problem in the near future, which will be experienced by existing power systems. For example, the plug-in electric vehicle (PEV) and/or the plug-in hybrid electric vehicle (PHEV) are in embryonic stage worldwide. Then, their common uses in residence are more than double the average load demand of household [4]. It is also reported that five thousand PHEVs impose additional charging load of up to 10 or $100 \mathrm{MW}$ on the grid by single-phase normal charging or three-phase fast charging, respectively. On the other hand, more than 17 million cars are already registered in Korea nowadays [5]. It implies that the additional power of 34 GW must be supplied if only $10 \%$ of these cars is replaced with the PEVs or PHEVs, and this corresponds to about $45.9 \%$ of the existing capacity of $74 \mathrm{GW}$ in the country [6]. Therefore, the increasing demand makes the existing power system saturated, and it requires system upgrade [7]. The DGs can provide an effective solution in smartly solving the aforementioned problem with the short construction time as well as its quick response to the peak load. In particular, they are strategically located and operated to reduce system losses, to reinforce grids, and to improve system reliability and efficiency [8]-[10]. The availability of renewable-energybased DGs depends on their conditions. To overcome this problem, several studies have been carried out to improve their availability by integrating different types of DGs and energy storage devices $[11,12]$. According to the studies of the Electric Power Research Institute (EPRI) and Natural Gas Foundation, it is expected that $30 \%$ of power generation in the U.S. will be supplied by DGs in the near future [13]. In spite of their several benefits, installation of DGs to the power grid requires careful considerations for several factors such as stability, reliability, protection coordination, power loss, power quality issues, etc. [14], [15]. Most of all, before multiple DGs are connected to the power grid, the selection of their optimal locations and sizes is very important in order to maximize the beneficial effects of the DGs

The aim of this paper is to combine previous studies of optimization for sizing and location of distributed generation. Investigating the optimum location and size by using Particle Swarm Optimization (PSO). Comparing the results for different methods.

The objective of the thesis is to study the location and sizing for this work.

1. To review and study of present existing methods.

2. To develop the mathematical algorithm of the proposed distribution system.

3. To investigate the optimum location and size of distributed generators in MATLAB/SIMULINK environment. 


\section{PRESENT SCENARIO OF DISTRIBUTED GENERATION IN INDIA}

The electrical sector in India has an installed capacity of $249488.31 \mathrm{MW}$ as of 30th June 2014 which is very high as compared to the installed capacity of $1362 \mathrm{MW}$ as of 31 st December 194. Still it is anticipated that India will face electricity shortages of $5.1 \%$ at base loads and $2 \%$ at peak load hours during 2014. With the increase in circuit kilometers, Transmission and Distribution losses (T\&D) are also increasing, which are accounted to $23.97 \%$ of total generation during 2011-12. This has become one of the main limitations for centralized power generation. On the other hand, the increased concern for generating electricity with low carbon emissions (Green Power), tending power sector to move from conventional methods of electricity generation using fossil fuels to alternative techniques. It is estimated that the required installation capacity by 2030 would reach $772 \mathrm{GW}$ (considering $8 \%$ growth in gross domestic product) (shown in Figure 1).

To bridge the gap between supply and demand by reducing Aggregate Technical and Commercial (AT\&C) losses and carbon emissions, there is a need to include renewable and non-renewable (small scale)power generations located nearer to load centers known as distributed generation (DG) ) (shown in Figure 2).

India has about 300 sunny days in a year. So, this solar energy can be utilized for generating electricity. The total grid connected solar capacity has reached $2631.93 \mathrm{MW}$ as of $31 \mathrm{st}$ march, 2014 ) (shown in Figure 3).

Wind energy based power generation is one of the best alternatives for conventional fossil fuel based power generation to reduce carbon foot prints. In terms of installed capacity India stood in fifth position with $21136.40 \mathrm{MW}$ as of 31st march, 2014 ) (shown in Figure 4).

The total installed capacity of biomass cogeneration is 4013.55MW, out of which major contribution is from bagasse (waste from sugar mills). It is estimated that, installed capacity can be increased to $5000 \mathrm{MW}$ if sugar mills adopt new cogeneration technologies.

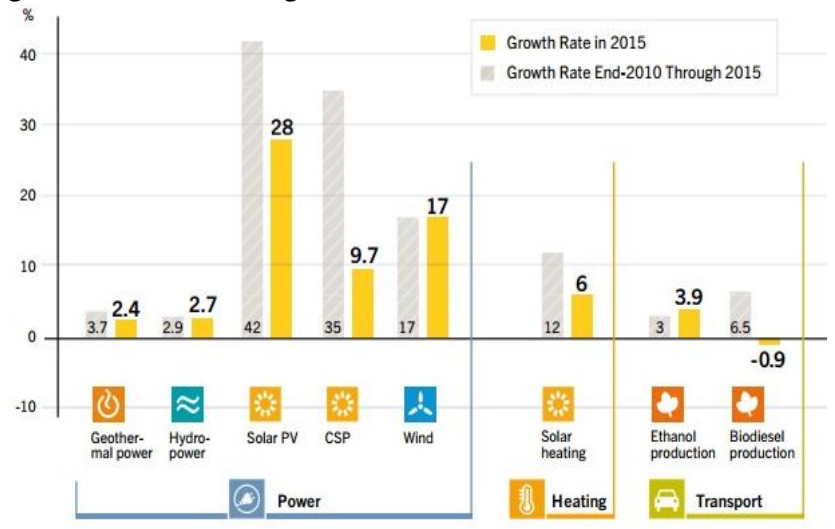

Fig 1: Average annual growth rates of renewable energy capacity and bio fuels production, end-2010 to end-2015
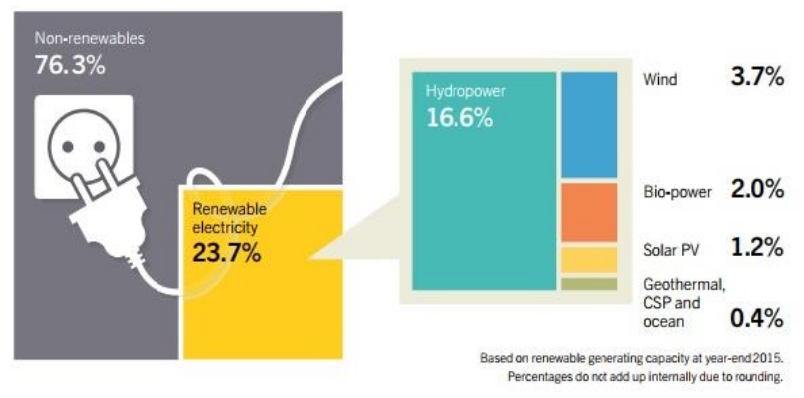

Fig 2: Estimated Renewable energy share of Global electricity production, End 2015

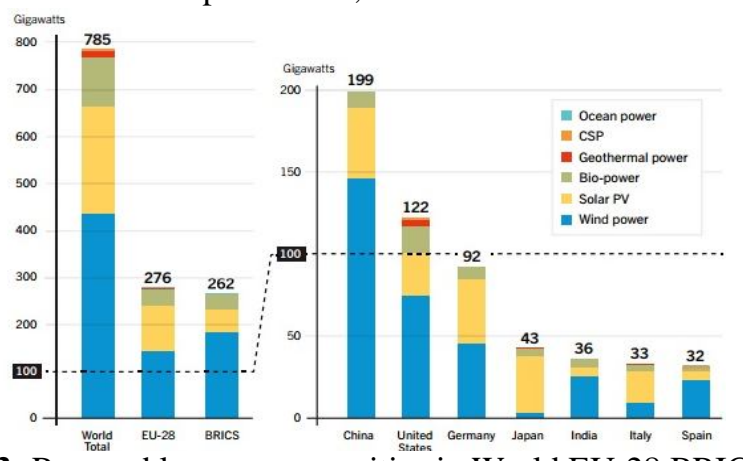

Fig 3: Renewable power capacities in World,EU-28,BRICS and top seven countries, End -2015

\section{HYDROPOWER}

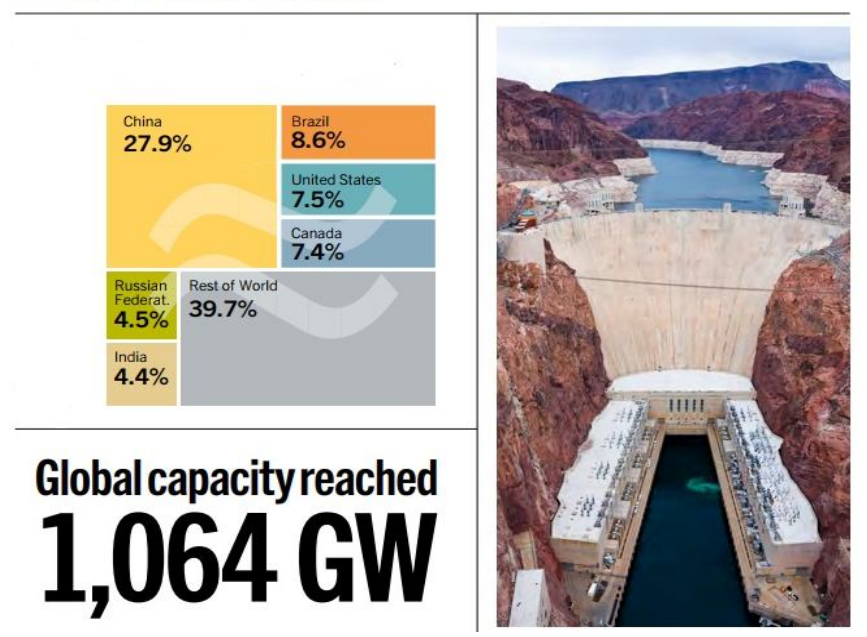

Fig 4: Hydropower Global capacity, shares of top six countries and rest of World, 2015

\section{METHODOLOGY}

In general, existing power plants are located far from consumer areas, and this condition results in a large amount of power loss on the power system. Installation of DGs can reduce the power loss if their proper locations are selected. To determine the optimal locations of multiple DGs, the IEEE benchmarked 31-bus system shown in Fig. 5 is used as a test system [1], [16]. The system in Fig. 1 is now analyzed for two different cases with respect to generator or load [17]. In other words, powers flow from the $k$ th generator to numerous loads in the first case, and they flow from several generators to the lth load in the second case. These two conditions are shown in 
Figs. 6 and 7, respectively. The associated parameters are defined as follows:

1) $P k$ : power supplied by the $k$ th generator in a power network;

2) $P l$ : power consumed by the $l$ th load in a power network;

3) $P k$,l: power flowing from the $k$ th generator to the $l$ th load;

4) Fjl,k: power flowing from the $k$ th generator to the $l$ th load through bus $j$ connected to the $l$ th load;

5) $F k j$, l: power flowing from the $k$ th generator to the $l$ th load through bus $j$ connected to the $k$ th generator.

In a combination of two cases described previously, the system in Fig. 5 can be expressed by the simplified circuit shown in Fig. 8 with the consideration of only power generations and load consumptions.

The branch between buses $i$ and $j$ in Fig. 8 can be represented with the simplified unit circuit as shown in Fig. 9. Then, the total power loss of the entire system can be calculated by summing the losses of all branches whenever the DG is connected to any bus [1]. In other words, the system in Fig. 8 can be simplified as a circuit in Fig. 9 by focusing on the relationship between the DG and the power loss. In the same manner, the entire power system (Fig. 5) can also be simplified. In DAPSO2, if there were many particles far away from the global best position, then the velocities should be given a larger value. If there were many particles near the global best position, then the velocities should be given a smaller value. DAPSO1 only adjusts the velocity of the certain particle, but in DAPSO2, the velocities of all particles are adjusted together.

The general flow of DAPSOs and the flowchart of DAPSO are shown as follows.

Step 1. Initialization of a population of particles with random positions and velocities

Step 2. Evaluation of particles.

Step 3. Calculate the distance from each particle to the global best position and save the farthest distance in the memory.

Step 4. Adjust particle's velocity according to its distance from itself to the global best position.

Step 5. Update particle's position by the adjusted velocity.

Step 6. Repeat Step.2 Step.5 until termination criteria are met.

\section{Particle Swarm Optimization:}

Evolutionary computation, offers practical advantages to the researcher facing difficult optimization problems. These advantages are multifold, including the simplicity of the approach, its robust response to changing circumstance, its flexibility, and many other facets. The evolutionary algorithm can be applied to problems where heuristic solutions are not available or generally lead to unsatisfactory results. As a result, evolutionary algorithms have recently received increased interest, particularly with regard to the manner in which they may be applied for practical problem solving. Usually grouped under the term evolutionary computation or evolutionary algorithms, they find the domains of genetic algorithms [2], evolution strategies [6], [7], evolutionary programming [1], and genetic programming [3]. They all share a common conceptual base of simulating the evolution of individual structures via processes of selection, mutation, and reproduction. The processes depend on the perceived performance of the individual structures as defined by the problem. Compared to other global optimization techniques, evolutionary algorithms (EA) are easy to implement and very often they provide adequate solutions. The flow chart of an EA is illustrated in Fig. 9. A population of candidate solutions (for the optimization task to be solved) is initialized. New solutions are created by applying reproduction operators (mutation and/or crossover). The fitness (how good the solutions are) of the resulting solutions are evaluated and suitable selection strategy is then applied to determine which solutions are to be maintained into the next generation. The procedure is then iterated. For several problems a simple Evolutionary algorithm might be good enough to find the desired solution. As reported in the literature, there are several types of problems where a direct evolutionary algorithm could fail to obtain a convenient (optimal) solution $[4,5,9,10]$.

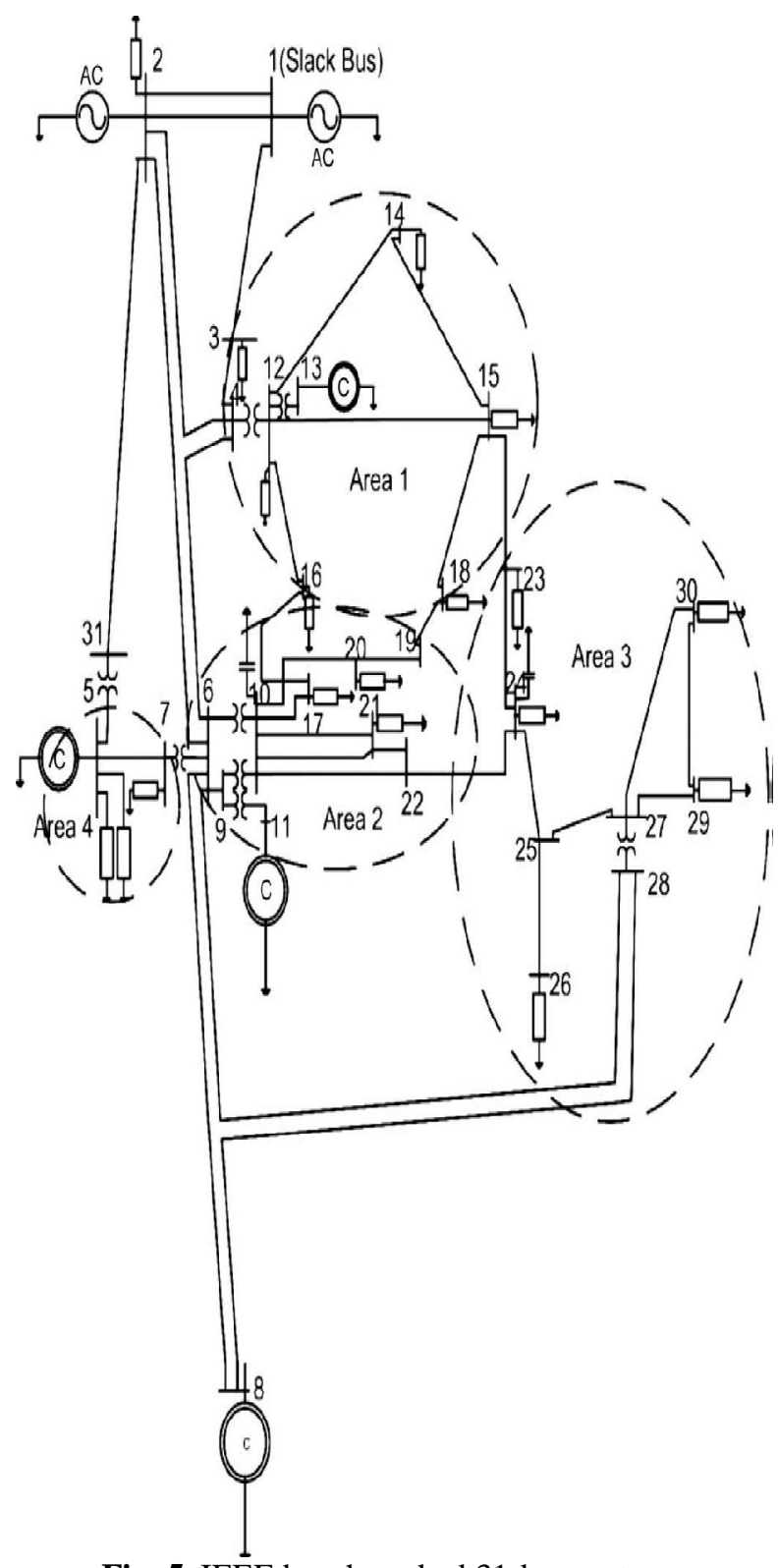

Fig. 5. IEEE benchmarked 31-bus system. 


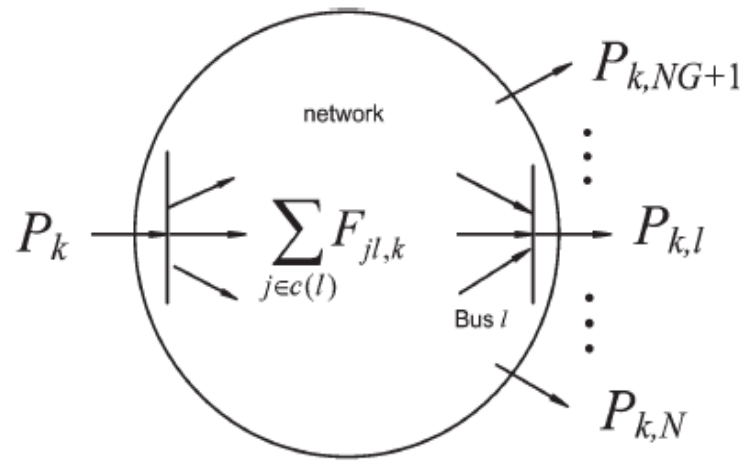

Fig. 6. Power flow from the $k$ th generator to the several

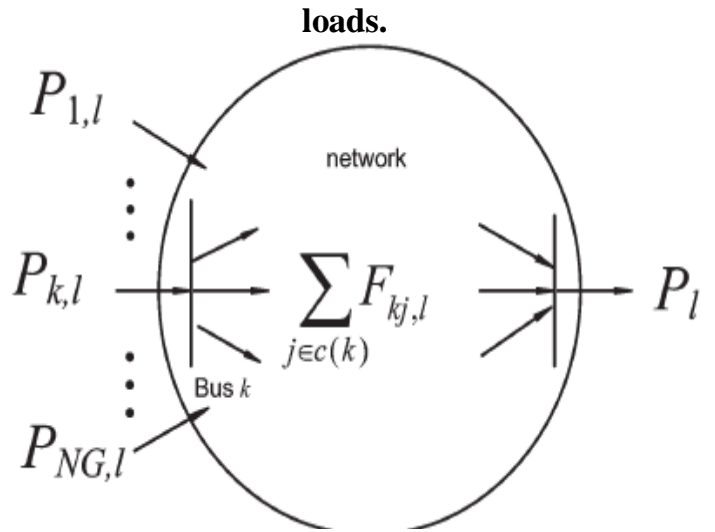

Fig. 7. Power flow from the several generators to the $l$ th load.

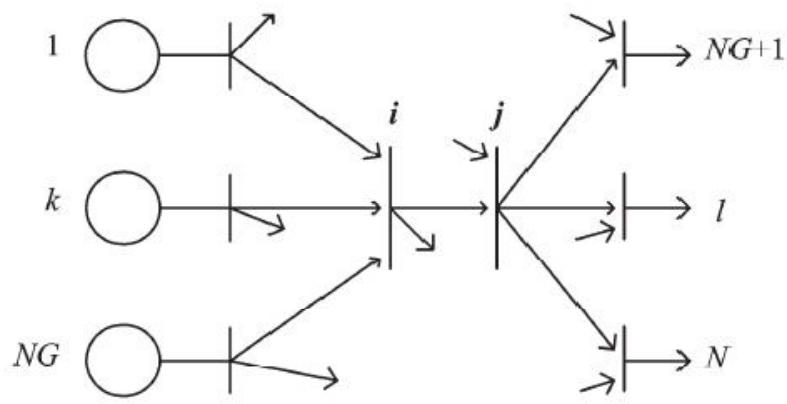

Fig. 8. Simplified circuit with only power generations and consumptions.

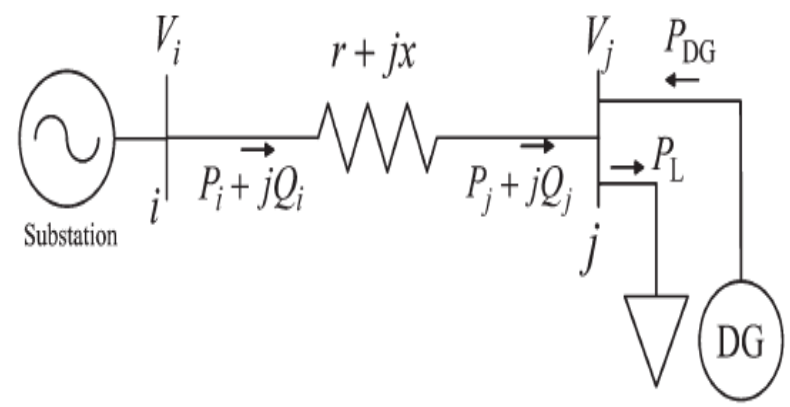

Fig. 9. Simplified unit circuit between two buses.

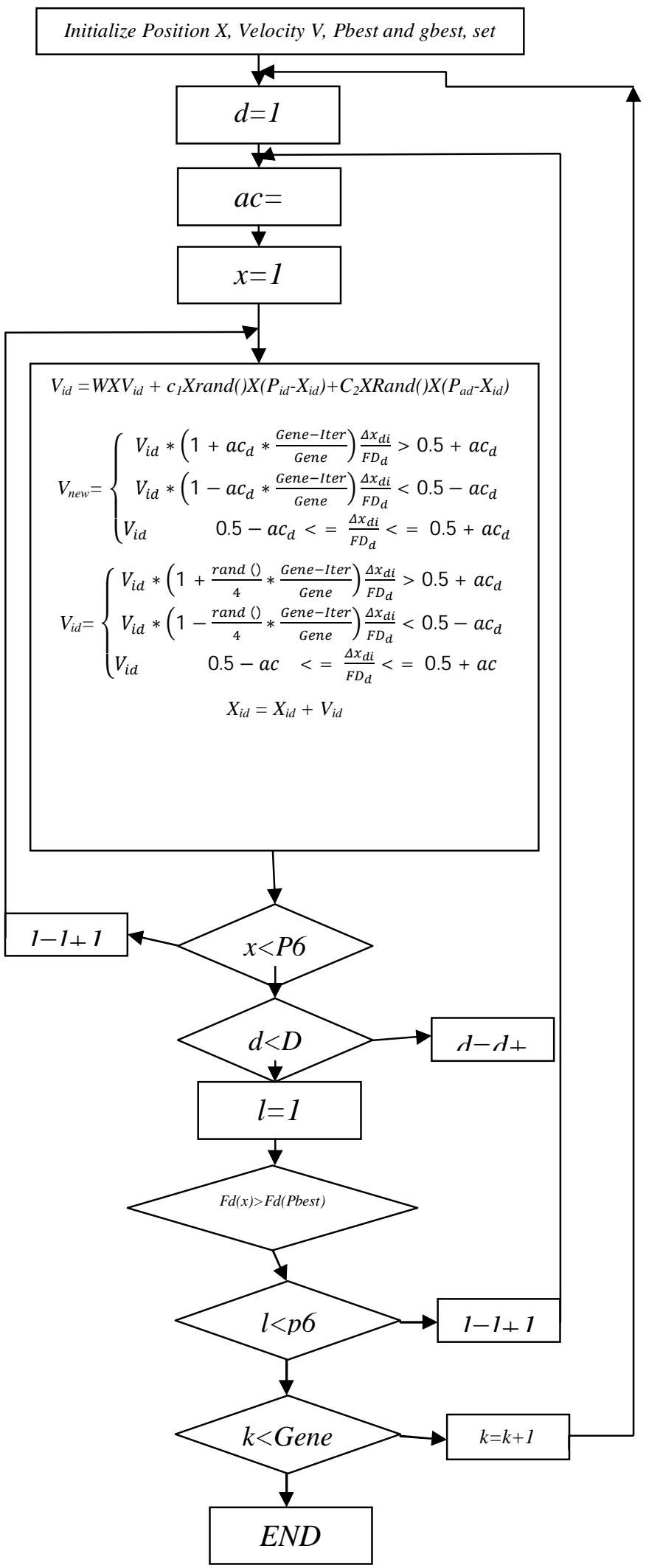

Fig. 10. Flowchart of DAPSO.

In Fig. $10, \mathrm{x}_{1}, \mathrm{x}_{2}$ and $\mathrm{x}_{3}$ all have difference distance from itself to global best position. $X_{1}$ drops within the radius of $(0.5-\mathrm{ac})^{*}$ $\mathrm{FD}_{\mathrm{d}}$. The distance from $\mathrm{x}_{2}$ to global best position is between $(0.5-\mathrm{ac})^{*} \mathrm{FD}_{\mathrm{d}}$ and $(0.5+\mathrm{ac})^{*} \mathrm{FD}_{\mathrm{d}} . \mathrm{x}_{3}$ drops beyond the radius 
of $(0.5+\mathrm{ac}) * \mathrm{FD}_{\mathrm{d}}$ in DAPSO1. In DAPSOs, we define the "long distance" as the distance from the particle to the global best beyond $(0.5+\mathrm{ac})^{*} \mathrm{FD}_{\mathrm{d}}$ and the "short distance" as the distance from the particle to the global best is smaller than (0.5- ac)* $\mathrm{FD}_{\mathrm{d}}$. In DAPSO1, the particles far away from the global best should be given larger value of velocity so it may explore an unknown region, whereas those close to the global best should be given smaller value of velocity so that it may exploit the neighborhood of the global best.

In DAPSO2, if there were many particles far away from the global best position, then the velocities should be given a larger value. If there were many particles near from the global best position, then the velocities should be given a smaller value. DAPSO1 only adjusts the velocity of the certain particle, but in DAPSO2, the velocities of all particles are adjusted together.

The general flow of DAPSOs and the flowchart of DAPSO are shown as follows.

Step 1. Initialization of a population of particles with random positions and velocities

Step 2.Evaluation of particles.

Step 3. Calculate the distance from each particle to the global best position and save the farthest distance in the memory.

Step 4. Adjust particle's velocity according to its distance from itself to the global best position.

Step 5. Update particle's position by the adjusted velocity.

Step 6. Repeat Step.2 Step.5 until termination criteria are met.

\section{RESULT AND DISCUSSION}

Optimized parameter value:

Line no. 66.00

Distance from line: 0.25

Voltage : $1.28 \mathrm{pu}$

Power: $15.00 \mathrm{MW}$

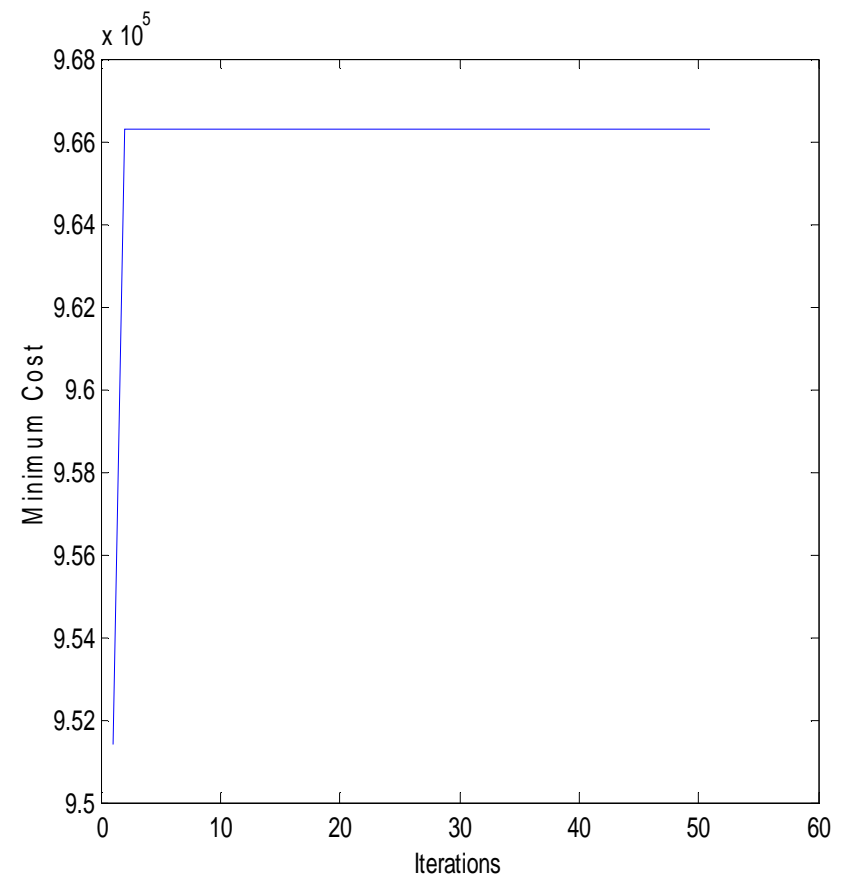

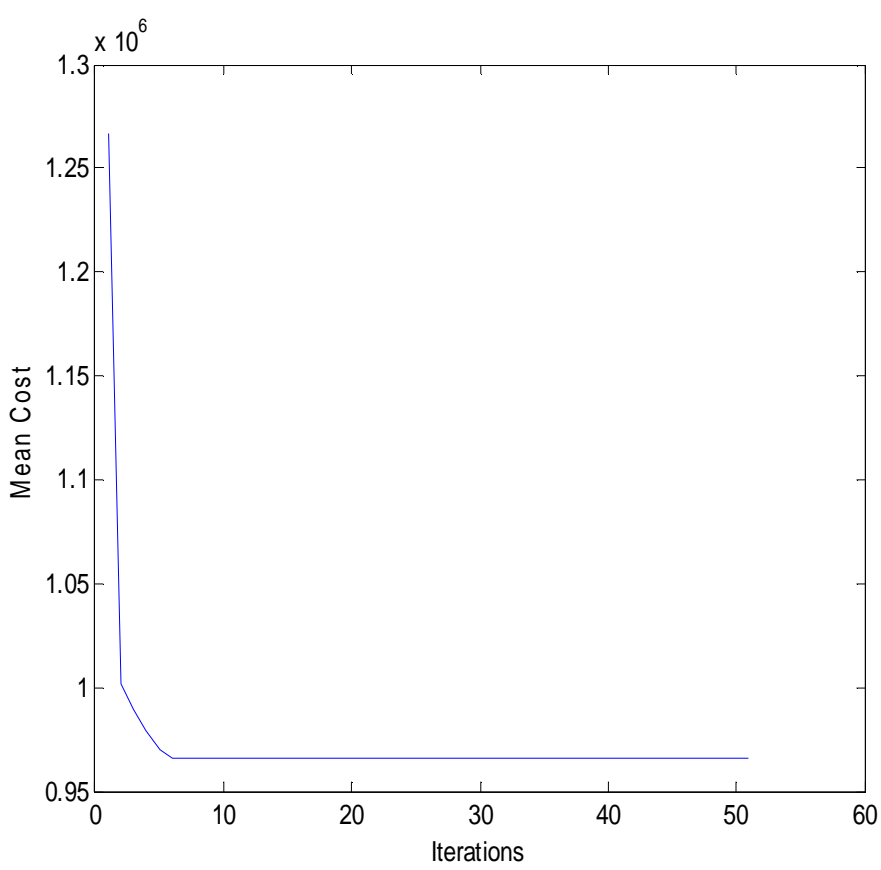

Fig. 12: Convergence Plot

Figure 13 shows various cost finally obtained by 10 particle based optimized solution at the end of optimum search.

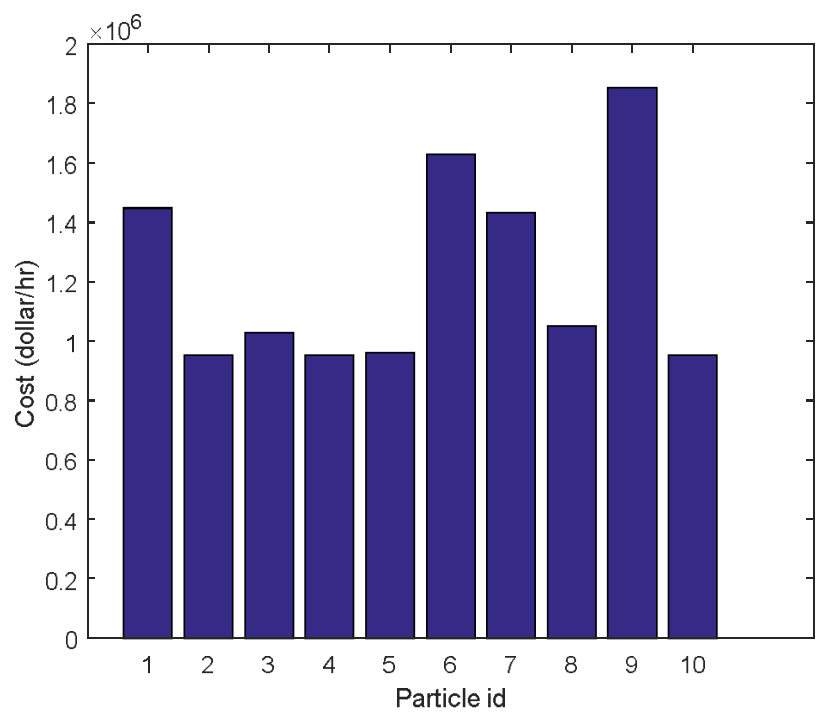

Fig 13: Cost obtained at different particle id solution by PSO

Figure 14(a) to shows the parametric value of all the optimized 10 particle at respective id obtained on reaching the final round of optimization search in terms of DG location as per line id, its distance from to bus for line id, it voltage rating in pu and its rated power in MW.

Similarly at different iteration and number of particles several times the PSO optimization algorithm is run for several times and best optimized solutions with better cost and lower losses are considered. The comparative values wrt 57 bus and optimized 58 bus with DG placement are shown in figure 15 .

Fig. 11: Minimum cost vs. iterations 


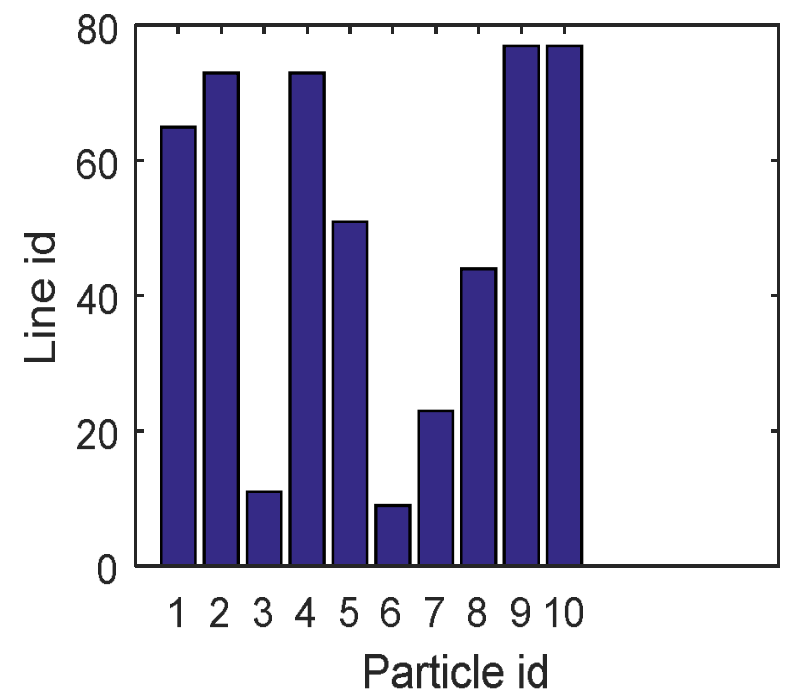

Figure 14(a): Line id of optimized particles

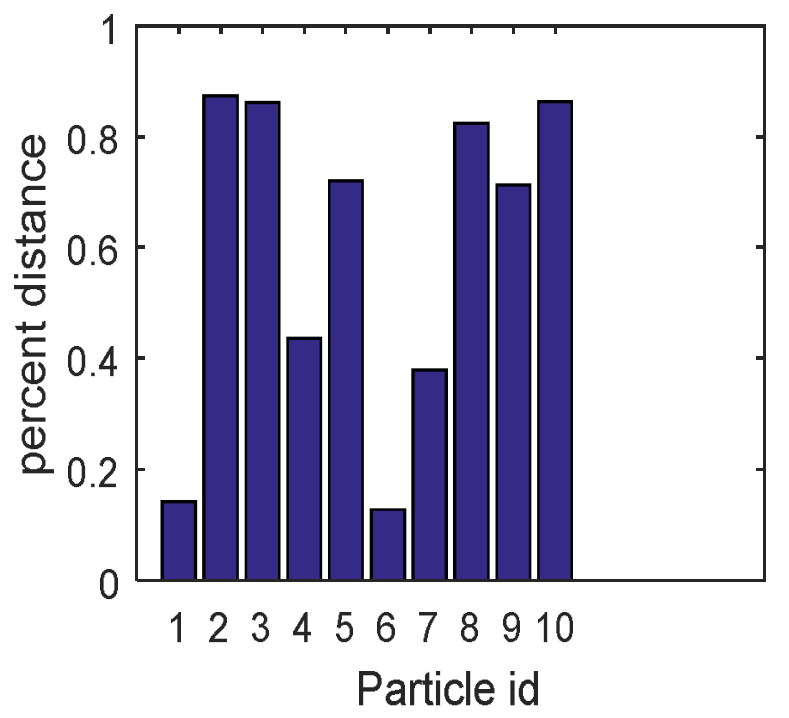

Fig 14(b): percent distance of optimized particles

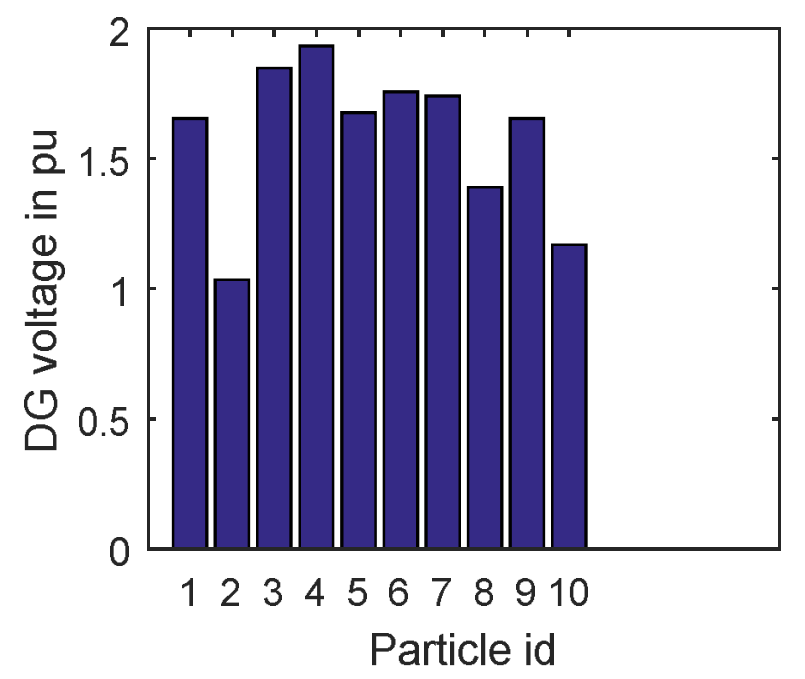

Fig 14 (c): DG voltage of optimized particles

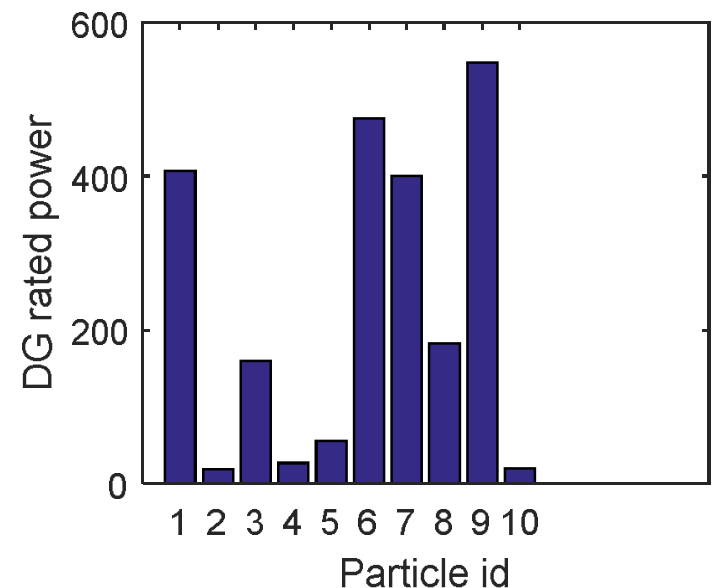

Fig 14(d): DG rated power of optimized particles

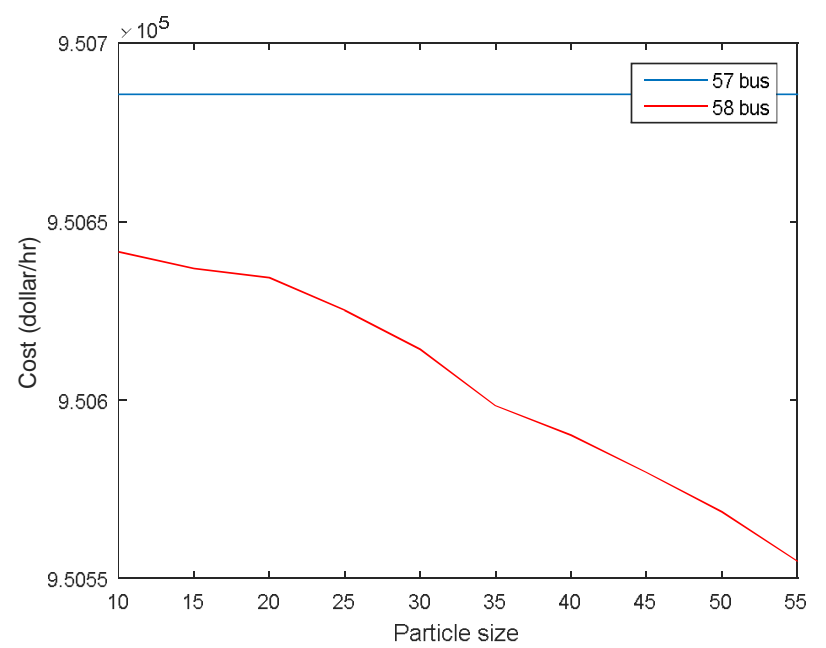

Fig 15: Selected optimized result with better performance cost wrt 57 (blue) and optimized 58 bus systems.

Table 1: Comparative result

\begin{tabular}{|c|c|}
\hline $\begin{array}{l}\text { Cost of generation in } \\
\text { original } 57 \text { bus: } \\
950685.6 \$ / \mathrm{h}\end{array}$ & $\begin{array}{l}\text { Cost of generation } \\
\text { in optimized } \mathbf{5 8} \text { bus: } \\
941390.08 \$ / \mathrm{h}\end{array}$ \\
\hline $\begin{array}{l}\text { Losses: } \\
\text { 27.394MW } \quad \text { and } \\
\text { 85.925MVAR }\end{array}$ & $\begin{array}{l}\text { Losses: } \\
\text { 27.394MW } \\
\text { 263.95MVAR }\end{array}$ \\
\hline
\end{tabular}

\section{CONCLUSION}

The PSO based optimum DG parameter estimator is designed using MATLAB programming algorithm. It has been proved that this optimization algorithm is quite effective for rapidly finding the changes required in insertion of additional DG's location, voltage and power rating in both the simulated and real-world power system scenarios considered. The new optimization method has demonstrated an ability to not only rapidly find large changes to power system modes, but has also been able to identify the mode which has changed. Multisite measurements can be also used to provide greater confidence in the detection alarming. This has significant implications for power utility intervention strategies. Importantly, the method is computationally efficient and can easily be implemented in real-time. 


\section{REFERENCES}

[1] S. H. Lee and J. W. Park, "Selection of optimal location and size of multiple distributed generations by using Kalman filter algorithm", IEEETrans. Power Syst., vol. 24, no. 3, pp. 1393-1400, Aug. 2009.

[2] H. Farhangi, "The path of the smart grid", IEEE Power Energy Mag.,vol. 8, no. 1, pp. 18-28, Jan./Feb. 2010.

[3] A. A. Chowdhury, S. K. Agarwal, and D. O. Koval, "Reliability modeling of distributed generation in conventional distribution systems planning and analysis", IEEE Trans. Ind. Appl., vol. 39, no. 5, pp. 14931498,Sep./Oct. 2003.

[4] A. Ipakchi and F. Albuyeh, "Grid of the future", IEEE Power Energy Mag., vol. 7, no. 2, pp. 52-62, Mar./Apr. 2009.

[5] Statistics Korea. (2010). Car Registration Status, Daejeon, South Korea. [Online]. Available: http://www.index.go.kr/egams/stts/jsp/potal/stts/PO_STTS_Id xMain.jsp?idx_cd=1257\&bbs=INDX_001\&clas_div=A

[6] Korea Power Exchange. (2010). Demand and Supply Result, Seoul, South Korea. [Online]. Available: http://www.kpx.or.kr/KOREAN/htdocs/main/sub/bidYesterda yList.jsp?cmd $=$ \& curpage $=103$

[7] Y. G. Hegazy, M. M. A. Salama, and A. Y. Chikhani, "Adequacy assessment of distributed generation systems using Monte Carlo simulation", IEEE Trans. Power Syst., vol. 18, no. 1, pp. 48-52, Feb. 2003.

[8] D. Singh, R. K. Misra, and D. Singh, "Effect of load models in distributed generation planning", IEEE Trans. Power Syst., vol. 22, no. 4, pp. 2204-2212, Nov. 2007.

[9] W. El-Khattam, Y. G. Hegazy, and M. M. A. Salama, "An integrated distributed generation optimization model for distribution system planning]",IEEE Trans. Power Syst., vol. 20, no. 2, pp. 1158-1165, May 2005.

[10] C. Wang and M. H. Hehrir, "Analytical approaches for optimal placement of distributed generation sources in power systems", IEEE Trans. PowerSyst, vol. 19, no. 4, pp. 20682076, Nov. 2004.

[11] R. Karki and R. Billinton, "Reliability/cost implications of PV and wind energy utilization in small isolated power systems", IEEE Trans. EnergyConvers., vol. 16, no. 4, pp. 368-373, Dec. 2001.

[12] S. Teleke, M. E. Baran, S. Bhattacharya, and A. Q. Huang, "Rule-based control of battery energy storage for dispatching intermittent renewable sources", IEEE Trans. Sustain. Energy, vol. 1, no. 3, pp. 117-124, Oct. 2010.

[13] R. Sharma, Anurag, " Load Forecasting using ANFIS A Review", International Journal of Research and Development in Applied Science and Engineering, Volume 20, Issue 1, 2020.

[14] Anurag, R. Sharma, " Load Forecasting by using ANFIS", International Journal of Research and Development in Applied Science and Engineering, Volume 20, Issue 1, 2020.

[15] R. Sharma, Anurag, " Detect Skin Defects by Modern Image Segmentation Approach, Volume 20, Issue 1, 2020.

[16] Anurag, R. Sharma, " Modern Trends on Image Segmentation for Data Analysis- A Review", International Journal of Research and Development in Applied Science and Engineering, Volume 20, Issue 1, 2020.
[17] Young Soo Jang et. al., "Development of the costeffective, miniaturized vein imaging system with enhanced noise reduction", International Journal of Advanced Trends in Computer Science and Engineering, Volume 8, No.6, November - December 2019.

[18] Irma T. Plata1, et. al., "Development and Testing of Embedded System for Smart Detection and Recognition of Witches' Broom Disease on Cassava Plants using Enhanced Viola-Jones and Template Matching Algorithm", International Journal of Advanced Trends in Computer Science and Engineering, Volume 8, No.6, Volume 8, No.5, September October 2019. 